\title{
Enhanced Oil Recovery Screening of Some Libyan Oil Reservoirs in Sirte Basin Oil Fields
}

\author{
Abdulrrazg Y. Zekri ${ }^{1}$, Mohamed S. Nasr ${ }^{2}$ and Said M. Edbieb ${ }^{3}$
}

\begin{abstract}
Tertiary oil recovery, which is the subject of this study, is employed after the two primary and secondary recovery mechanisms are exhausted. In the tertiary recovery phase, the oil in the reservoir is recovered by means of gas miscible displacement, chemical and thermal flooding. Each of these processes has their limitations to be used in the reservoir according to their applicability to the reservoir rock and fluid properties and to the condition of the reservoir.

In this study, a giant oil field in Libya is investigated to find out its suitability to the well-known applicable enhanced oil recovery methods. The previous reservoir studies for this field indicated that the estimated ultimate oil recovery factor is around $33.6 \%$. Therefore, a substantial amount of oil remains in the ground after the primary and the secondary processes are exhausted which is targeted for EOR processes. One of the objectives of the current study is to investigate and select appropriate EOR tertiary processes and to determine their feasibilities and implementation in the field in order to improve the ultimate oil recovery from the reservoir.
\end{abstract}

The available fluid and rock laboratory raw data has been gathered, reviewed, calibrated and analyzed using special techniques. The screening analysis was then carried out through Excel spreadsheets and visual basic programs which were used for averaging capillary pressure and relative permeability data and specialized computer software programs such, EORgui and PVTi and other related software programs.

The results from the screening criteria using EORgui software indicated that Micellar (Surfactant and Polymer) flooding is the most suitable EOR technique for this field. The estimated oil recovery from surfactant and Polymer flooding over the primary and secondary recoveries are $13.5 \%$ and $12.5 \%$ of oil in place respectively. In addition, the results from the screening criteria indicate that the second ranking EOR process is to be implemented in the field is the carbon dioxide $\left(\mathrm{CO}_{2}\right)$ miscible flooding. Using well-known correlations to predict $\mathrm{CO}_{2}$ minimum miscibility pressure (MMP) for the field, an average of $4520 \mathrm{psi}$ is obtained. Therefore, it is recommended that using chemical flooding followed by polymer injection is the suitable EOR processes to be successfully implemented in this field..

Keywords - Oil Recovery Screening, Libyan Oil Reservoirs

\section{INTRODUCTION}

Enhanced oil recovery (EOR) is an oil recovery method conducted in oil reservoirs by the injection of materials not normally present in the reservoir. This definition covers all modes of oil recovery processes (drive, push-pull, and well

Abdulrrazg Y. Zekri, Professor of Petroleum Engineering, University of United Arab Emirates, Al Ain, UAE.

Mohamed S. Nasr, Professor of Petroleum Engineering, University of Tripoli, Tripoli, Libya.

Said M. Edbieb, Professor of Petroleum Engineering, University of Tripoli, Tripoli, Libya. treatments) and most oil recovery agents. The definition does not restrict EOR to a particular phase (primary, secondary, or tertiary) in the producing life of a reservoir. Primary recovery is an oil recovery method using the natural drive mechanisms: solution gas, water influx, and gas cap drives, or gravity drainage. Secondary recovery refers to techniques, such as gas or water injection, whose purpose is mainly to raise or maintain reservoir pressure. Tertiary recovery is any technique applied after secondary recovery. Nearly all EOR processes have been at least field tested as secondary displacements. Enhanced oil recovery is one of the technologies needed to maintain reserves.

The EOR definition does exclude water-flooding but is intended to exclude all pressure maintenance processes. The distinction between pressure maintenance and displacement is not clear, since some displacement occurs in all pressure maintenance processes. Moreover, agents such as methane in a high-pressure gas drive, or carbon dioxide in a reservoir with substantial native $\mathrm{CO}_{2}$, do not satisfy the definition, yet both are clearly EOR processes.3,4 EOR is essential because of the amount of oil to which it is potentially applicable. This EOR target oil is the amount unrecoverable by conventional means. A large body of statistics shows that conventional ultimate oil recovery (the percentage of the original oil in place at the time for which further conventional recovery becomes uneconomic) is about $35 \%$.

Today the technology and economic on the average leaves two barrels of oil in the ground for each barrel recovered worldwide. Worldwide many enhanced oil recovery techniques (EOR) have been proposed and implemented to improve the oil recovery factor and to recover the remaining oil from reservoirs after exhausting the primary and secondary reservoir drive mechanisms.

\section{A. Enhanced Oil Recovery (EOR) Processes}

Enhanced oil recovery (EOR) processes include all methods that use external sources of energy and/or materials to recover oil that cannot be produced, economically by conventional means. These EOR methods include the following; water flooding, thermal, chemical and miscible methods which are illustrated in detail in Table 1. 
TABLE I: ENHANCED OIL RECOVERY (EOR) PROCESSES INCLUDING ALL METHODS

\begin{tabular}{|l|l|l|l|}
\hline \multicolumn{1}{|c|}{ Waterflood } & \multicolumn{1}{c|}{ Thermal } & \multicolumn{1}{c|}{ Chemical } & \multicolumn{1}{c|}{ Miscible gas } \\
\hline $\begin{array}{l}\text { Maintains reservoir } \\
\text { pressure \& physically } \\
\text { displaces oil with } \\
\text { water moving through } \\
\text { the reservoir from } \\
\text { injector to producer. }\end{array}$ & $\begin{array}{l}\text { Reduces } \mathrm{S}_{\text {orw }} \text { by } \\
\text { steam distillation and } \\
\text { reduces oil viscosity. }\end{array}$ & $\begin{array}{l}\text { Reduces } \mathrm{S}_{\text {orw }} \text { by } \\
\text { lowering water-oil } \\
\text { interfacial tension, and } \\
\text { increases volumetric } \\
\text { sweep efficiency by } \\
\text { reducing the water-oil } \\
\text { mobility ratio. }\end{array}$ & $\begin{array}{l}\text { Reduces } \text { Sorw }_{\text {by }} \\
\text { developing miscibility } \\
\text { with the oil through a } \\
\text { vaporizing or } \\
\text { condensing gas drive } \\
\text { process. }\end{array}$ \\
\hline
\end{tabular}

The goal of any enhanced oil recovery process is to mobilize "remaining" oil. This is achieved by enhancing oil displacement and volumetric sweep efficiencies. Oil displacement efficiency is improved by reducing oil viscosity (e.g., thermal floods) or by reducing capillary forces or interfacial tension (e.g., miscible floods). Volumetric sweep efficiency is improved by developing a more favorable mobility ratio between the injectant and the remaining oil-in place (e.g., polymer floods, water alternating- gas processes WAG). It is important to identify remaining oil and the mechanisms that are necessary to improve recovery prior to implementing an EOR process.

Upon initial discovery, a reservoir generally produces via natural drive mechanisms. If there is not enough natural reservoir energy for wells to flow, some form of artificial lift may be used to provide the energy to lift produced fluids to surface. In addition to conventional oil recovery processes, there are a variety of methods that are available to improve recovery efficiency. These can be categorized into three fundamental types:

- Enhanced Oil Recovery

- Strategic Wellbore Placement

- Production / Injection Control

There is not a single method which can be considered a "cure all" for recovering additional oil from every reservoir. Each method has its specific application, and a variety of methods may be used in a specific reservoir simultaneously. Before selecting the appropriate methods, a thorough reservoir study should be conducted to properly characterize the reservoir and to analyze historical production characteristics and alternatives.

Enhanced oil recovery is actually a competitor with conventional oil recovery because most producers have assets or access to assets in all of the categories illustrated in Figure 1. The competition then is joined largely on the basis of economics in addition to reserve replacement. At the present, many EOR technologies are competitive with drilling-based reserve additions. The key to economic competitiveness is how much oil can be recovered with EOR.

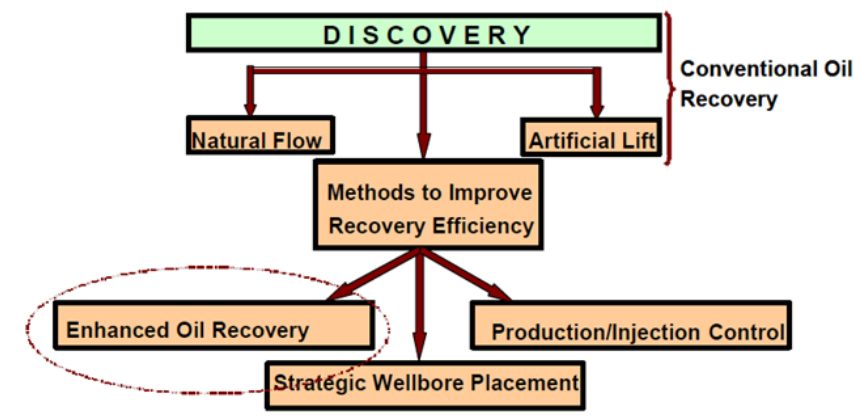

Fig. 1: Oil Production Categories

\section{B. Objectives of the Study}

In the studied field oil production has increased considerably after five years from the start of water injection. This oil production increase was reached after maintaining an average volume of water injection of $400,000 \mathrm{bbl}$ per day. This water injection program which is a secondary recovery mechanism is considered to be successful artificial method for improving oil recovery from the reservoir. The water injection program was initiated in the field for pressure maintenance and to supplement the depleted aquifer energy of the reservoir. On the other hand, the ultimate recovery factor of the field is around 50 $\%$ of which indicates substantial amount of oil remains in the ground after primary and secondary processes are exhausted.

Due to the suitable nature of the reservoir rock for EOR processes and the current state of economics and technology, it is suggested that an EOR study should be conducted to find the suitability of these EOR processes in this reservoir. One of the objectives of the current study is to investigate and select the appropriate EOR tertiary processes and to determine their feasibilities and implementation in the field in order to improve the ultimate oil recovery from the reservoir.

\section{EOR SCREENING CRITERIA}

The screening process begins with gathering as much reservoir data as possible and developing a coherent package to compare with the screening criteria for various EOR methods. After narrowing the choices, the evaluation moves into the laboratory to investigate rock and fluid properties, and to conduct flow studies. Engineers and geoscientists use the available data to develop updated static and dynamic reservoir models, and to simulate the effects of different EOR methods in order to choose the optimum one.10, 11 The following steps should be followed for selecting and evaluating any EOR process.

- Screening guides or criteria are among the first items considered when a petroleum engineer evaluates a candidate reservoir for enhanced oil recovery.

- Sophisticated and complex numerical models are used in industry to evaluate the suitability of a reservoir for $\mathrm{CO} 2$ flooding.

- The choice of enhanced oil recovery processes is based on technical and economic data. 


\section{FIELD PRODUCTION HISTORY}

Up to now the cumulative oil production from the field amounts at some $33 \%$ of the original oil in place (OOIP) and a water cut value of $29 \%$. The field produces volatile oil $\left(41^{\circ} \mathrm{API}\right)$ from Nubian sandstones. The crude is paraffinic with a wax content of $36.7 \%$ and a high pour point temperature 93 $0 \mathrm{~F}\left(34{ }^{\circ} \mathrm{C}\right)$. The rate decline and mature status of the field led the operating company management to investigate the feasibility of a tertiary gas injection project to improve the final oil recovery. Carbon dioxide, lean gas and enriched gas were tested with the aim of finding out the most efficient solvent miscible with the oil at the current reservoir conditions.

\section{RESULTS AND DISCUSSION}

The Available fluid and rock laboratory raw data of the field has been reviewed, analyzed and adjusted using common techniques for the adjustment of the laboratory measured data. All the data has been presented in tabular and graphical forms in order to be ready for use in enhanced oil recovery screening criteria technique or any other technical use. The work was carried out through Excel spreadsheet and computer software programs such as Capillary Pressure, Relative Permeability, EORgui and PVTi.

\section{A. Enhanced Oil Recovery Screening of the Field}

The screening criteria followed for the selection of the suitable EOR recovery method is based on the criteria proposed by Taber and Aladasani.12,13,14 Figures 2 and 3 present detailed analysis of the screening process of this oil field. Results indicate that Micellar/Polymer flooding is the most suitable EOR technique for the field.

Based on the basic field properties $82 \%$ of the Micellar/Polymer process application requirements can be achieved compared with 56\% for Carbon Dioxide. Therefore, it is concluded that Surfactant chemical slug followed by Polymer slug is the suitable EOR flooding process for the field.

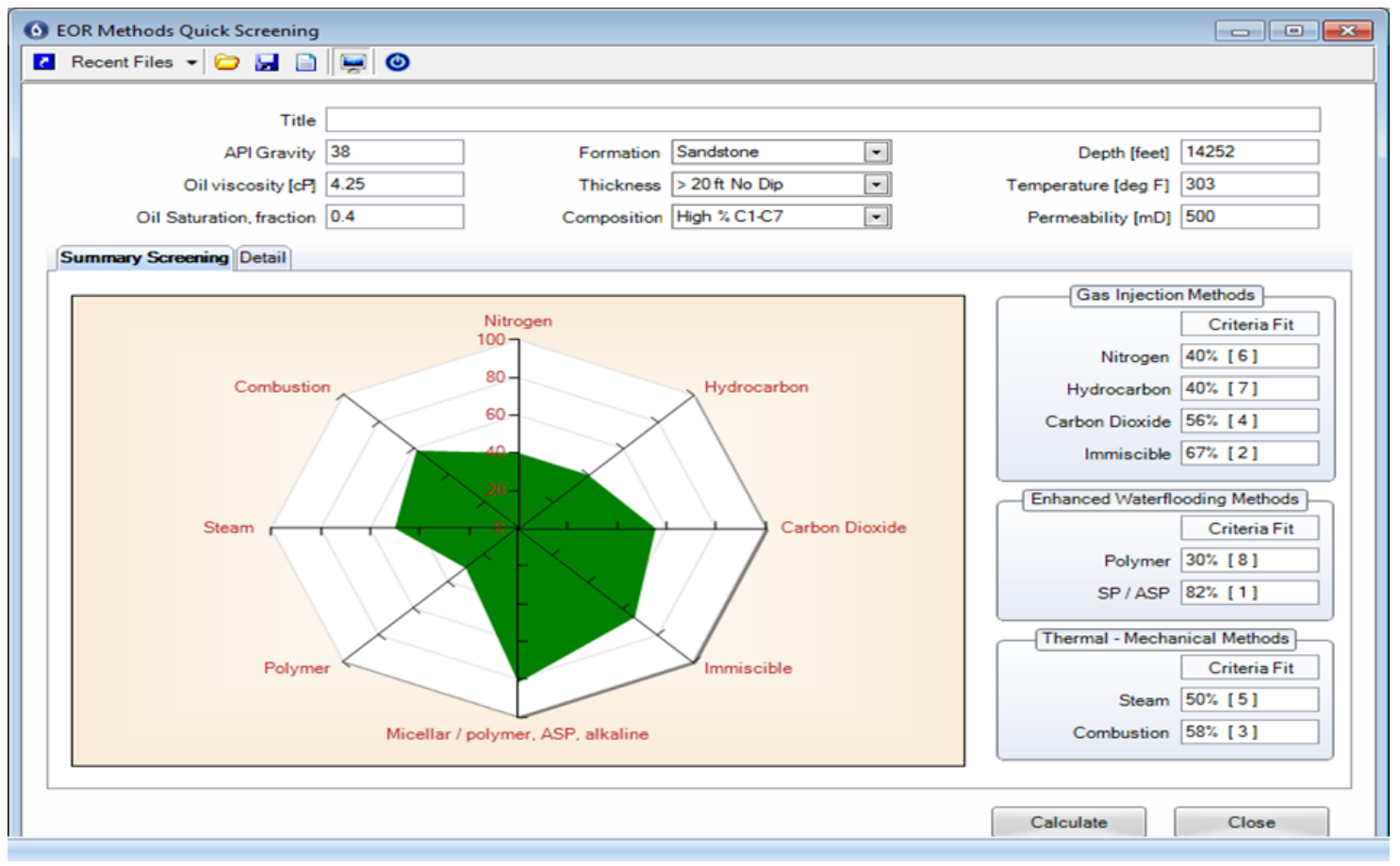

Fig. 2: Summary of Screening Results for the Studied Field 


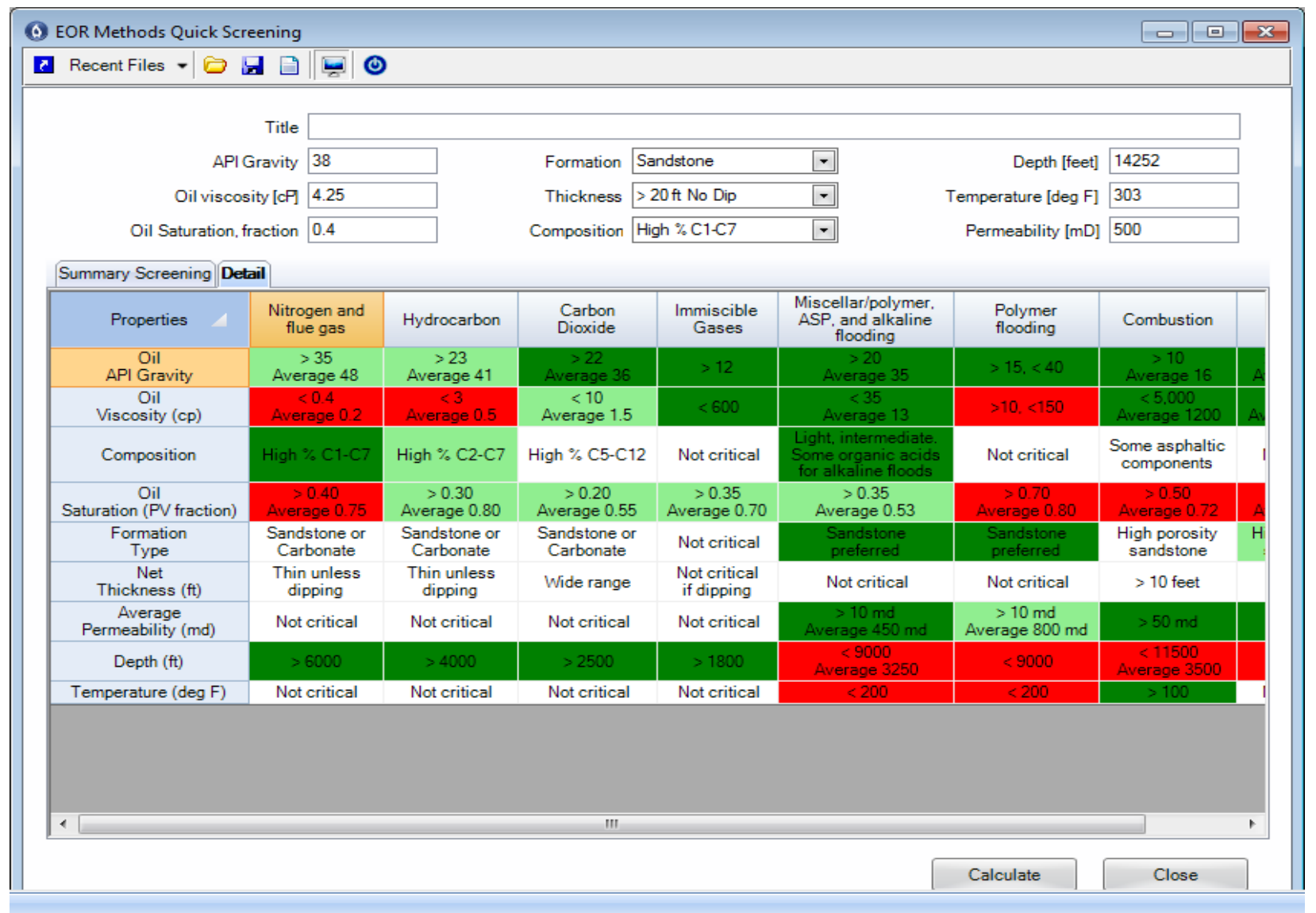

Fig. 1: Detailed Screening for the Studied Field

\section{B. Optimization of the Surfactant and the Polymer Flooding Slug Sizes}

A surfactant slug followed by slug of polymer to improve the volumetric seep efficiency is proposed as a technique for the field. The following are the results of different runs to optimize the slug sizes for the surfactant and the polymer. Keeping in mind that water will be driving the polymer and surfactant slugs. For the surfactant slug size optimization, the following five different slugs were tested: $0.2,0.5,0.7,1$ and 1.3 pore volumes. Results indicate that optimum surfactant slug size is 0.55 pore volume and expected addition oil recovery of $13.5 \%$ of oil in place.

In the other hand, for polymer slug size optimization, the following four different slug sizes were tested: $0.3,0.5,0.65$, and 0.8 pore volumes. Results indicate that optimum polymer slug size is 0.55 pore volume and expected addition oil recovery of $12.5 \%$ of oil in place. The optimization results of both processes are presented in Tables 2 and 3 and also plotted in Figures 4 and 5 for both surfactant and polymer flooding respectively.

.TABLE II: OPTIMUM SURFACTANT SLUG SIZES VERSUS RECOVERY FOR THE SURFACTANT FLOODING

\begin{tabular}{|c|c|}
\hline Surfactant Slug Size (PV) & Oil Recovery \\
\hline 0.2 & $8 \%$ \\
\hline 0.5 & $12 \%$ \\
\hline 0.7 & $13 \%$ \\
\hline 1 & $15 \%$ \\
\hline 1.3 & $16 \%$ \\
\hline
\end{tabular}




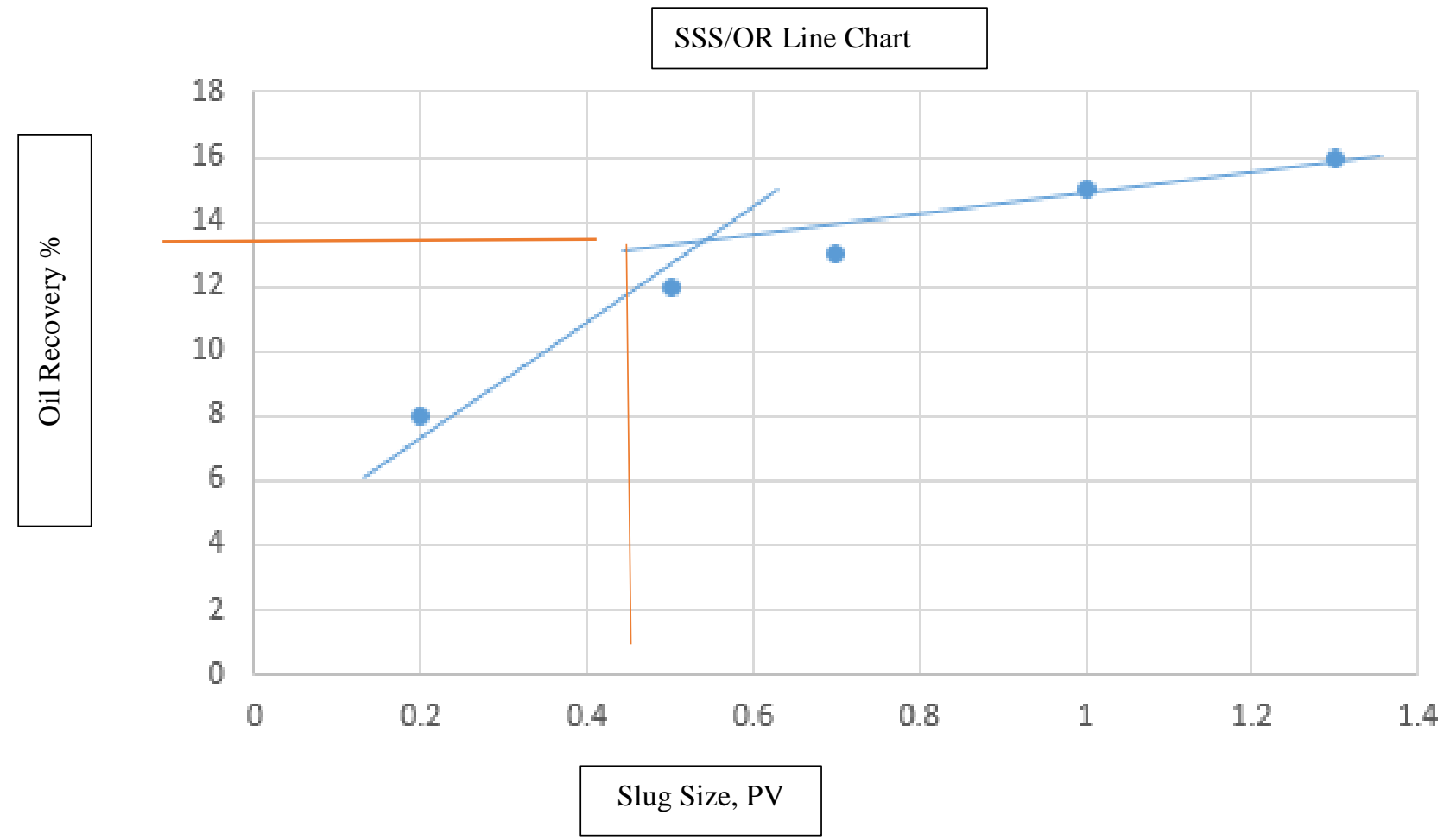

Fig. 4: Oil Recovery Result (Surfactant Slug Size)

TABLE III: OPTIMUM POLYMER SLUG SIZES VERSUS RECOVERY FOR THE POLYMER FLOODING

\begin{tabular}{|c|c|}
\hline Polymer Slug Size (PV) & Oil Recovery \\
\hline 0.3 & $11 \%$ \\
\hline 0.5 & $11.5 \%$ \\
\hline 0.65 & $12.4 \%$ \\
\hline 0.8 & $12.9 \%$ \\
\hline
\end{tabular}

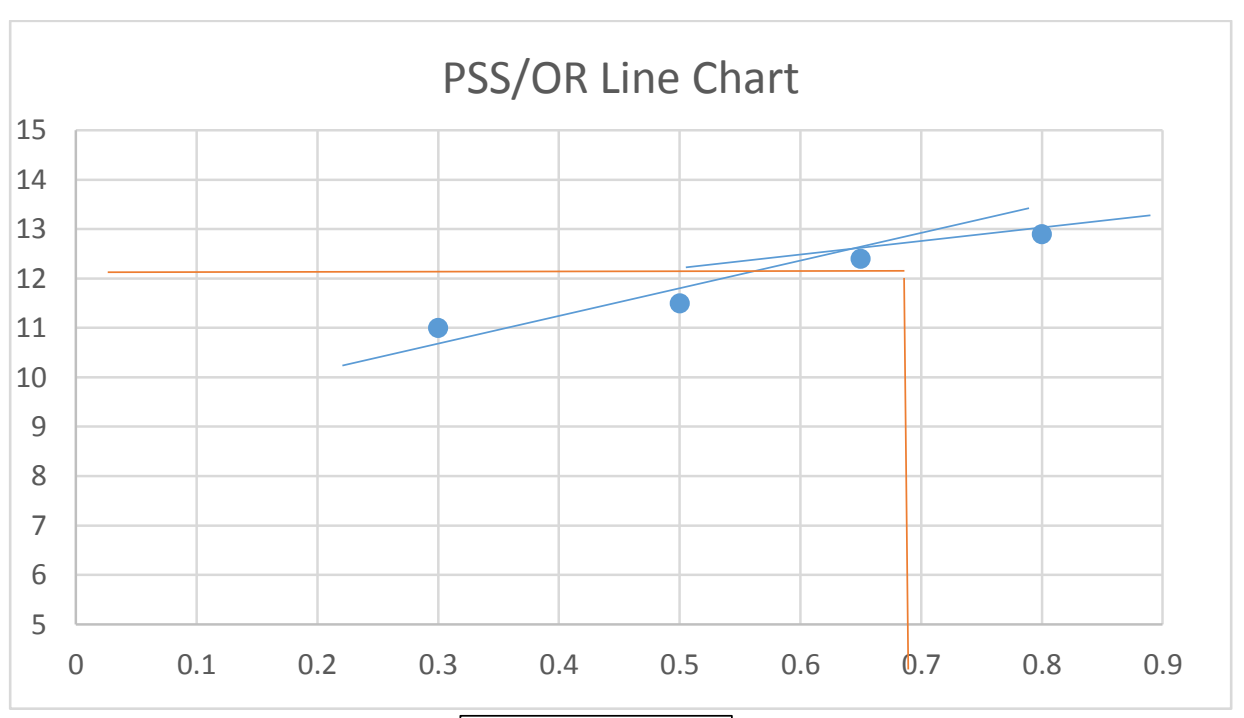

Slug Size, PV

Fig. 5: Oil Recovery Results (Polymer Slug Size) 


\section{CONCLUSION}

1. The experimental results from PVT, the capillary pressure as well as from the relative permeabilities were reviewed, analyzed and screened, which will be used for the selection of the suitable EOR methods using EORgui and PVTi software programs.

2. The analysis of the results of this study obtained from the output of the screening criteria of the software programs indicated that the Surfactant/polymer flooding is the most suitable technique for the field.

3 . The optimum slug sizes of the surfactant and the polymer chemicals that are proposed to be used to drive these chemicals through the reservoir are the same and were estimated to be around 55\% of pore volume. Water will be used to drive both surfactant and polymer slugs from the injection wells to the producing wells.

4. The estimated oil recovery from surfactant and Polymer flooding over the primary and secondary recoveries are $13.5 \%$ and $12.5 \%$ of original oil in place respectively.

5. Miscible Carbon Dioxide (CO2) flooding can be applied for the field with an estimated minimum miscibility pressure around 4520 psia.

6 . The obtained results from the use of these programs will enable the company to setup future EOR development plans to increase the oil recovery in the field.

7. It is recommended to conduct a study for the Carbon Dioxide flooding of the field and the results should be compared to the surfactant/polymer flood process to arrive at a definite conclusion with respect to the most appropriate EOR processes for the candidate field.

\section{REFERENCES}

[1] Lake, Larry W., Enhanced Oil Recovery, Englewood Cliffs, NJ. Prentice-Hall, 1989.

[2] Van Poollen, H. k., and Associates, Fundamentals of Oil Recovery (Tulsa, Oklahoma: Pennell, 1980.

[3] Latil, M., et al., Enhanced Oil Recovery (Houston, TX: Gulf, 1980.

[4] Brashear, J. P., A. B. Becker, and K. H. Biglarbigi, "Incentives Technology and EOR: Potential for Increased Oil Recovery at Lower Prices," SPE 17454, California Regional Meeting, Long Beach, CA, March 23-25, 1988.

[5] Anonymous, 2 002. 2002 Worldwide EOR Survey. The Oil and Gas Journal $100(15)$, pp. $72-83$.

[6] Anonymous, 2006. Special Report: 2006 Worldwide EOR Survey. The Oil and Gas Journal 104 (15), 46- 57.

[7] Anonymous, 2007. World Energy Outlook 2007. International Energy Agency. pp 76-93.

[8] Awan, A.R., Teigland, R., Kleppe, J., 2006. EOR survey in the North Sea. Proceedings of A SPE/DOE Symposium on Improved Oil Recovery, 22 26 April 2006, held at Tulsa, Oklahoma, U.S.A. (SPE 99546). https://doi.org/10.2118/99546-MS

[9] Koottungal, L., 2008. 2008 Worldwide EOR Survey. The Oil and Gas Journal 106 (15), 47, 59. Koottungal, Leena, 2010, Worldwide EOR survey. The Oil and Gas Journal 108 (14), pp 41-53.

[10] Parkinson, W.J. et al.: An Expert system for Screening Enhanced Oil Recovery Methods," Presented at 1990 AICHE Summer Meeting, San Diego, California August, 1990. pp. 19-22 https://doi.org/10.1016/0375-6505(90)90021-3

[11] Parkinson, W.J. et al.." Screening EOR Methods with Fuzzy Logic," Presented at 1991 International Reservoir Characterization Conference, Tulsa, Oklahoma, 3-5 November, 1991.

[12] Taber, J.J., Martin, F.D., and Seright, R.S.: "EOR Screening Criteria Revisited: Part 2 -Applications and Impact of Oil Process", (August 1996).
https://doi.org/10.2118/39234-PA

[13] Taber, J.J., Martin, F.D., and Seright, R.S.: "EOR Screening Criteria Revisited," Paper SPE 35385 Presented at the 1996 SPE/DOE Symposium on Improved Oil Recovery, Tulsa, Oklahoma, 21-24 April 1996.

[14] Al Adasani, Ahmed and Bai, Baojun, "Analysis of EOR Projects and Updated Screening Criteria", Journal of Petroleum Science and Engineering, Elsevier, 79, 2011, pp10-24. https://doi.org/10.1016/j.petrol.2011.07.005 